\title{
An analysis of skin prick test reactions in 656 asthmatic patients
}

\author{
D . J. HE N D R I C K ${ }^{1}, R$. J . D A V I E S ${ }^{2}$, \\ M. F. D'SOUZ A ${ }^{3}$, a nd J.PEPYS
}

Department of Clinical Immunology, Cardiothoracic Institute, Brompton Hospital, London SW3

\begin{abstract}
Hendrick, D. J., Davies, R. J., D'Souza, M. F., and Pepys, J. (1975). Thorax, 30, 2-8. An analysis of skin prick test reactions in 656 asthmatic patients. Of 656 asthmatic patients referred specifically for allergy assessments, $544(84 \%)$ gave positive immediate skin prick tests to at least one of 22 common allergens used routinely. Comparison of these skin test positive patients with the $102(16 \%)$ who were skin test negative showed a number of significant differences. The majority of the skin test positive patients $(52 \%)$ were less than 10 years old at the time of onset of the asthma, whereas, of the skin test negative patients, $56 \%$ were aged over 30 years at the time of onset. Seventy per cent reported rhinitis compared with $48 \%$ of the skin test negative patients, and $29 \%$ reported infantile eczema compared with $9 \%$. Symptoms attributed to house dust, pollens, and animals were noted two to three times more frequently by the skin test positive patients, while corticosteroid drugs had been used more commonly by the skin test negative patients (45\% compared with $35 \%$ ).

No significant differences were observed with the other factors studied, namely, history of urticaria or angio-oedema, family history of 'allergic' disease, and awareness of sensitivity to foods, aspirin or penicillin.

Prick test reactions in the skin test positive patients were most commonly seen to house dust or the acarine mite, Dermatophagoides farinae $(82 \%)$, followed by pollens $(66 \%)$, animal danders $(38 \%)$, foods $(16 \%)$, Aspergillus fumigatus $(16 \%)$, and other moulds $(21 \%)$. There was a highly significant association of positive history with positive prick test for all allergens studied.
\end{abstract}

\begin{abstract}
Although the association between immediate wealing skin reactions and asthma has been recognized for many years (Coca and Cooke, 1923), the specificity of these tests, their relation to etiology, and their clinical significance has been in dispute. Rackemann (1947) suggested that the presence of positive skin reactions on routine prick testing with common inhalant and food allergens should place the asthmatic into the extrinsic (allergic) category where usually the onset of symptoms is early in life and the prognosis more favourable than in the intrinsic (nonallergic) category (Rackemann and Edwards, 1952; Rackemann, 1958).
\end{abstract}

Raised serum IgE levels have been found in

Present addresses:

Department of Chest Diseases, United Oxford Hospitals

'Department of Medicine, St. Thomas' Hospital, London

'Department of Clinical Epidemiology and Social Medicine, St. Thomas' Hospital, London
$63 \%$ of allergic asthmatics compared to only $5 \%$ of intrinsic asthmatics (Johansson, 1967), and a good correlation has been demonstrated between the number of positive skin reactions to a routine number of allergens and the total amount of serum IgE (Stenius, Wide, and Seymour, 1972). Further, the weal size of the individual skin prick tests has been shown to correlate well with the amount of specific serum IgE for that allergen (Stenius et al., 1971).

Close correlations have also been demonstrated for a number of allergens between the clinical history, skin prick tests, serum levels of specific IgE, and bronchial provocation tests (Pepys, Chan, and Hargreave, 1968; McAllen, Assem, and Maunsell, 1970; Stenius et al., 1971). In some cases the combination of a positive clinical history with a positive skin prick test has shown an even closer correlation with bronchial provocation 
tests than has the serum level of specific IgE (Aas and Johansson, 1971). The clinical history and the results of skin prick tests may therefore be of considerable value in determining aetiological factors in asthma.

The purpose of this investigation was to compare allergic and other factors in two categories of asthmatic patients distinguished by the presence or absence of positive immediate skin prick tests, and to study the relationship between the presence of positive prick tests and the history of provocation by the appropriate allergens.

\section{MATERIALS AND METHODS}

PATIENTS The 656 patients were selected at random from those attending the clinical immunology outpatient department of the Brompton Hospital between 1969 and 1971. They had been referred by general practitioners, by other departments of the Brompton Hospital, and by other hospitals or chest clinics. The data were recorded on standardized questionnaires during the course of routine clinical assessment. The results were transferred to punch cards from which the analysis was made.

The patients were classified according to age at onset-group $1<10$ years, group $2 \quad 10-30$ years, group $3>30$ years. There were 365 males and 301 females.

HISTORY The diagnosis of asthma was accepted if there was a history of intermittent wheezing. In most cases reversible airways obstruction had been observed by the referring physician. The occurrence of other 'allergic' disease was similarly accepted from the history alone if the major clinical characteristics were described, namely, weeping, pruritic eruptions of the flexures within the first 12 months of life for infantile eczema; recurrent episodes of undue sneezing, nasal discharge or blockage for rhinitis; pruritic wealing eruptions for urticaria; and acute swelling of the face, lips, tongue or throat for angio-oedema.

A positive family history was recorded if at least one first-degree relative (parent, sibling or child) had asthma, rhinitis, infantile eczema, urticaria or angiooedema.

The use at any time of corticosteroid drugs in the management of the asthma was also noted.

The capacity of specific allergens to provoke symptoms was assessed from the history by a physician of the department before the skin tests were carried out.

SKIN PRICK TESTS These tests were carried out with a series of 22 routine allergens or allergen groups which fell into five classes:

1. House dust

Dermatophagoides farinae, $10 \mathrm{mg} / \mathrm{ml}$; house dust

2. Pollens

Grasses (B2); shrubs (B1); trees (B3)
3. Animal danders

Cat; dog; feathers; horse

4. Foods

Egg; fish; milk; nuts; wheat

5. Moulds

Alternaria; Aspergillus fumigatus; Aspergillus terreus; Candida; Cladosporium herbarum; Merulius lacrymans; Sporobolomyces; yeast

Controls

Carbol/saline; Gaine's dog meal; yeast.

All the allergens were prepared by Bencards Limited apart from the cat, dog, and horse extracts, which were obtained from Dome Limited, and $D$. farinae, which was made up in the Brompton laboratory (Stenius et al., 1971). Separate controls of Gaine's dog meal and yeast were used with this allergen as these constituted the media on which the mite was grown. Dermatophagoides pteronyssinus, which is chiefly responsible for the allergenicity of house dust in the UK, is less readily cultured, and extracts for skin tests were not readily available for routine use at the time of this study. Prick tests with extracts of $D$. farinae, however, have been shown to give comparable results (Pepys et al., 1968), and so this species was used as the source of Dermatophagoides allergen.

The volar aspect of one forearm was used but the skin at the edges, the wrist, and the antecubital fossa was avoided. The 22 routine prick tests together with controls were arranged in three rows in a standard order, the site of each test being marked by Biro. A gauge 25 needle (Gillette size No. 17) held at $45^{\circ}$ to the surface, bevel downwards, was pressed vertically and gently through a drop of test extract so that its point penetrated the epidermis and, on withdrawal, raised the skin. This method rarely drew blood. If it did, the test was repeated. A separate needle was used for each test. The distal row was prepared and tested first, followed by middle and proximal rows, thus avoiding smearing. When all the tests were completed absorbent tissue was carefully applied to remove the residual extract, and the sleeve was rolled down to keep the arm warm. The patient was instructed not to scratch, and the tests were read after 10 to 20 minutes.

A positive immediate (type 1) reaction was taken to be present when there was a measurable weal of $1 \mathrm{~mm}$ or more, surrounded by a flare in the absence of any equivalent reaction in the control test. Small weals were confirmed by palpation. A flare alone was disregarded. In cases of doubt, individual tests were repeated in triplicate. Reactions in patients with dermatographism were not included unless individual weal sizes were at least twice that of the control.

Patients were not tested if they had had any antihistamine drugs within the preceding 48 hours. Sodium cromoglycate, corticosteroids, catecholamines, and methylxanthines were not considered to be a bar to testing. 
STATISTics The $\chi^{2}$ test was used for all statistical comparisons.

\section{RESULTS}

Of the 656 patients in the series, $554(84 \%)$ gave positive immediate prick test reactions to at least one of the 22 routine common allergens. There was no immediate skin reactivity in the remaining $102(16 \%)$. There was a marked difference in the distribution according to age at onset of the asthma between skin test positive and skin test negative patients (Fig. 1). The relative proportions of skin test positive to skin test negative patients in each age group are shown in Figure 2.

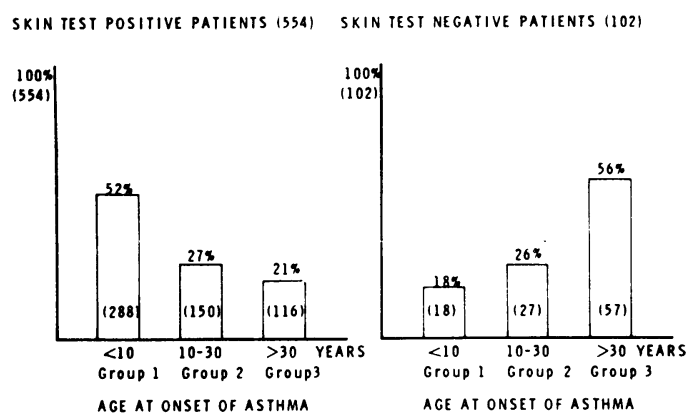

FIG. 1. Distribution of 656 asthmatic patients according to skin prick test reactivity and age at onset.
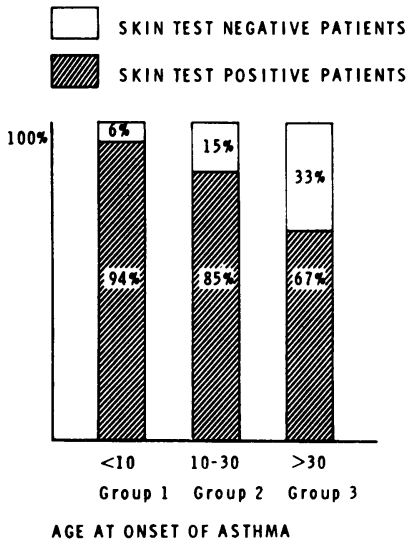

FIG. 2. Relative proportions of skin test positive to skin test negative patients in each age group.

HISTORY Table I shows the prevalences of other 'allergic' diseases, positive family history, previous use of corticosteroids, and possible provoking factors in both skin test positive and skin test negative patients. Rhinitis and eczema were significantly more common in the skin test positive subjects, as were histories of provocation by house dust, pollens, and animals $(P<0.001)$. The use of corticosteroids before presentation was more common in the skin test negative patients $(P<0.05)$. There were no significant differences with respect to urticaria or angio-oedema, family history of 'allergic' diseases or histories of provocation by foods, aspirin, and penicillin.

\section{T A B L E I} HISTORY

\begin{tabular}{|c|c|c|c|c|}
\hline & \multicolumn{2}{|c|}{$\begin{array}{c}\text { Skin Test } \\
\text { Positive }\end{array}$} & \multicolumn{2}{|c|}{$\begin{array}{l}\text { Skin Test } \\
\text { Negative }\end{array}$} \\
\hline & $\begin{array}{l}\text { No. } \\
554\end{array}$ & $\%$ & $\begin{array}{l}\text { No. } \\
102\end{array}$ & $\begin{array}{l}\% \\
100\end{array}$ \\
\hline $\begin{array}{l}\text { Other 'allergic' diseases } \\
\text { Rhinitis } \\
\text { Eczema } \\
\text { Urticaria/angio-oedema } \\
\text { Rhinitis and eczema } \\
\text { Rhinitis, eczema and } \\
\text { urticaria/angio-oedema }\end{array}$ & $\begin{array}{r}388 \\
159 \\
88 \\
121 \\
\\
26\end{array}$ & $\begin{array}{r}70 \\
29 \\
16 \\
22 \\
5\end{array}$ & $\begin{array}{r}49 \\
9 \\
11 \\
5 \\
0\end{array}$ & $\begin{array}{r}48 \\
9 \\
11 \\
5 \\
-\end{array}$ \\
\hline Family history & 212 & 38 & 41 & 40 \\
\hline Corticosteroids & 192 & 35 & 46 & 45 \\
\hline $\begin{array}{l}\text { History of provoking factors } \\
\text { House dust } \\
\text { Pollens } \\
\text { Animals } \\
\text { Foods } \\
\text { Aspirin } \\
\text { Penicillin }\end{array}$ & $\begin{array}{r}297 \\
199 \\
156 \\
150 \\
23 \\
22\end{array}$ & $\begin{array}{r}54 \\
36 \\
28 \\
27 \\
4 \\
4\end{array}$ & $\begin{array}{r}20 \\
11 \\
8 \\
22 \\
4 \\
9\end{array}$ & $\begin{array}{r}20 \\
11 \\
8 \\
22 \\
4 \\
9\end{array}$ \\
\hline
\end{tabular}

SKIN PRICK TESTS The reactions given by the skin test positive patients are shown in Table II

Prick test reactions in the series as a whole were most commonly seen to house dust $(59 \%)$ and D. farinae $(58 \%)(69 \%$ giving reactions to one or the other or both), followed by pollens $(56 \%)$, animal danders $(32 \%)$, foods $(14 \%)$, A fumigatus $(13 \%)$, and other moulds $(18 \%)$.

Of the 168 skin test positive patients whose skin was unreactive to house dust, all but eight

T A B L E I I

PRICK TEST REACTIONS IN SKIN TEST POSITIVE PATIENTS

\begin{tabular}{l|r|r}
\hline & No. & $\%$ \\
\hline House dust and/or D. farinae & 554 & 100 \\
House dust & 454 & 82 \\
D. farinae & 386 & 70 \\
Pollens & 380 & 69 \\
Animal danders & 365 & 66 \\
Foods & 209 & 38 \\
A.fumigatus & 89 & 16 \\
Other moulds & 86 & 16 \\
Single positive & 116 & 21 \\
Multiple positives & 111 & 20 \\
& 443 & 80 \\
\hline
\end{tabular}


gave positive prick test reactions to $D$. farinae, grass pollen or $A$. fumigatus. The use of these four allergens alone would consequently have detected $546(99 \%)$ of the 554 skin test positive patients. No other combination of four individual allergens would have produced as high a yield.

SEX Males were more common than females $(3: 2)$ in the skin test positive patients whose asthma began under the age of 10 years, but the sexes were distributed evenly in all other age groups. There were significant differences between the skin test positive males and females with regard to histories of provocation by pollens (males $32 \%$, females $40 \%-\mathrm{P}<0.05$ ), animals (males $22 \%$, females $36 \%-\mathrm{P}<0.001$ ), and foods (males $23 \%$, females $32 \%-\mathrm{P}<0.025$ ) but not by house dust, aspirin or penicillin. Prick test reactions to animal danders were also more common in females (males $33 \%$, females $44 \%-\mathrm{P}<0.01$ ), but with the other allergens little difference was seen between the sexes, as was the case with family history and the previous use of corticosteroids. The numbers of skin test negative patients were generally too small for significant differences between the sexes or age groups to be apparent.

AGE Eczema, but not rhinitis or urticaria/angiooedema, was reported less by the older skin test positive age groups (group $142 \%$, group $218 \%$, group $310 \%-\mathrm{P}<0.001)$. A history of animal provocation in these patients was also reported less with increasing age at onset of the asthma (group $135 \%$, group $227 \%$, group $313 \%$ $\mathbf{P}<0.001$ ), while aspirin sensitivity appeared to become more common (group 1 1\%, group $25 \%$, group $39 \%-\mathrm{P}<0.001)$. There were no significant variations with age in the previous use of corticosteroids in either skin test positive or negative patients, but in the latter a positive family history was obtained less commonly in the older age groups (group $166 \%$, group $244 \%$, group 3 $30 \%-\mathrm{P}<0.025)$.

With all test extracts, except foods, the prevalence of positive prick test reactions decreased with increasing age at onset, though in the case of $A$. fumigatus this was not statistically significant. The proportion giving positive reactions in group 3 was approximately two-thirds of that in group 1. The older age groups showed a corresponding increase in the proportion of patients giving a single positive skin reaction (group 1 $14 \%$, group $224 \%$, group $330 \%-\mathrm{P}<0.001$ ).
ASSOCIATION OF HISTORY WITH SKIN PRICK TEST REACTIVITY (Fig. 3, Table III) With all allergens, those patients with positive histories gave appropriate positive skin test reactions in greater proportion than those with negative histories. Conversely, again with all allergens, those showing positive skin test reactions gave positive histories in greater proportion than those without skin sensitivity. The details are presented in Fig. 3. The association of positive history with positive skin reaction was highly significant for all allergens $(\mathrm{P}<0.001-$ Table III $)$.

T A B L E I I I

SIGNIFICANCE OF ASSOCIATION OF POSITIVE HISTORY WITH POSITIVE PRICK TEST IN SKIN TEST POSITIVE PATIENTS

\begin{tabular}{c|c|c|c|c|c|c}
\hline & $\begin{array}{c}\text { House Dust } \\
\text { and/or } \\
\text { D. farinae }\end{array}$ & $\begin{array}{c}\text { House } \\
\text { Dust }\end{array}$ & D. farinae & Pollens & Animals & Foods \\
\hline$\chi^{2}$ & $\begin{array}{c}19.84 \\
\mathbf{0}\end{array}$ & $\begin{array}{c}11.84 \\
0.0005\end{array}$ & $\begin{array}{c}11.88 \\
0.001\end{array}$ & $\begin{array}{c}32.22 \\
0.0005\end{array}$ & $\begin{array}{c}62.75 \\
0.0005\end{array}$ & $\begin{array}{l}20.53 \\
0.0005\end{array}$ \\
\hline
\end{tabular}

\section{DISCUSSION}

The proportion of this series of asthmatic patients falling into the immediate skin prick test positive and hence extrinsic category $(84 \%)$ is rather higher than the $64 \%$ showing 'allergic factors' reported by Williams et al., (1958), 68\% by Pearson (1958) or $54 \%$ by Ford (1969). This may be due in part to the use of a single defining criterion-prick test reactivity-and in part to the selection of patients, all of whom were specifically referred for allergy assessment. In a further series of 1,000 asthmatics, Pepys (1973) found $78 \%$ to be skin test positive. Smith (1973) performed prick tests with a similar range of allergens on a similarly selected group of children aged 5 to 18 years who suffered from asthma and other 'allergic' diseases. At least one positive reaction was obtained in $95 \%$, which may be compared to the group in this study aged under 10 years at onset of their asthma, $94 \%$ of whom gave positive reactions.

Comparison of the skin test positive with skin test negative patients revealed a number of significant differences. The incidence of skin test positive asthma appeared to diminish with increasing age, while that of skin test negative asthma appeared to increase. It is possible that the age differences between the skin test positive patients (predominantly children) and the skin test negative patients (predominantly adults) were independently partly responsible for some of the other 

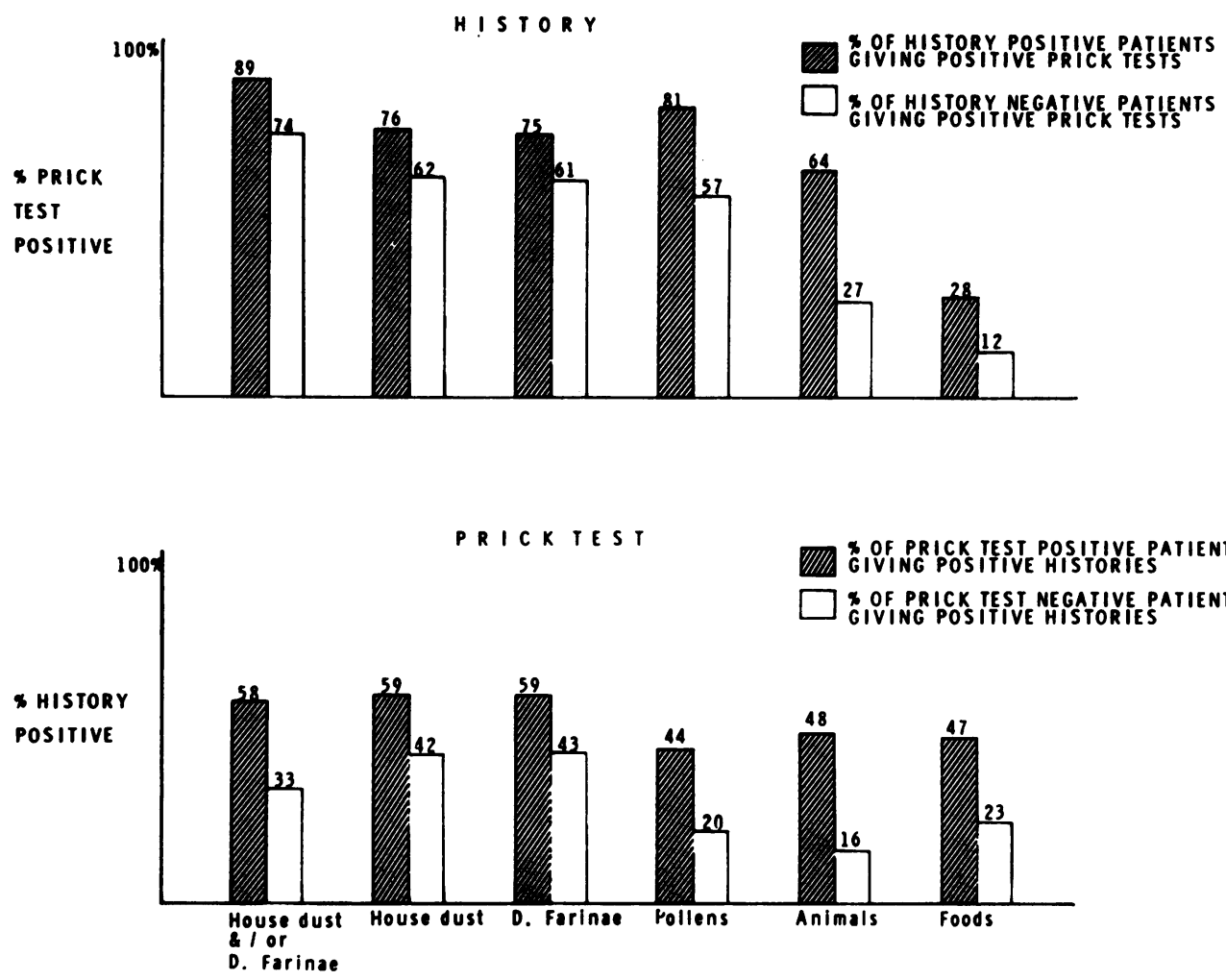

FIG. 3. Association of history with prick test reactivity in skin test positive patients.

differences observed, and some significant variations with age were indeed seen. The numbers in the skin test negative age groups, however, were too small for direct statistical comparisons with each skin test positive age group.

Rhinitis was reported half as commonly again by the skin test positive patients, and infantile eczema appeared to be three times as common, while provocation of 'allergic' symptoms by house dust, pollens, and animals (inhaled allergens) was reported two to three times more commonly. Overall $77 \%$ of the skin test positive patients gave positive histories of allergy to one or other of the allergens studied compared to $47 \%$ of the skin test negative patients.

While the skin test positive patients differed from the skin test negative patients in the above respects, no significant differences were observed with the other factors studied, namely, history of urticaria or angio-oedema, family history of 'allergic' disease, and history of provocation by foods, aspirin, and penicillin (ingested allergens). The similar percentages $(38 \%$ and $40 \%$ respec- tively) reporting a positive family history of 'allergic' disease in at least one first-degree relative are particularly interesting, Forgacs (1973) 3 having recently reported the same observation. Pearson (1958) showed little difference in family history of asthma between asthmatics showing predominant psychogenic or infective factors and those who were predominantly allergic. Pepyso (1973), however, considered the total numbers of first-degree relatives affected by asthma, rhinitiso or infantile eczema, and showed a positive correla- $N$ tion with the skin reactivity (number of positiven prick tests) of asthmatic patients.

Prick test reactions were most commonly seen to house dust or $D$. farinae followed by pollens, animal danders, and foods. The same order of pre-s? cedence was reported by Pearson (1958), Ford (1969), and Smith (1973), Pearson and Fordō having considered other criteria of allergy in addition to the prick test. The same order was seen in the skin test positive patients of the present series with respect to history of provocation by each of the allergen groups, but in the् 
skin test negative patients food sensitivity was reported with the greatest frequency.

The well recognized higher prevalence of asthma in boys was seen in skin test positive patients aged under 10 years at onset, but the sexes were evenly balanced in all other groups. Similar findings were reported by Ford (1969), though other workers have found a bias in favour of females in older asthmatics (Pearson, 1958; Williams et al., 1958). Otherwise little variation was seen between the sexes. Skin prick test positive females gave positive histories of allergy to pollen, animals, and foods half as commonly again as did males, and this was accompanied by a higher prevalence of prick test reactivity to animal danders.

In the skin test positive patients there was a highly significant association $(P<0.001)$ of positive history with positive skin prick test for all the allergens studied, positive prick tests being generally more common than positive histories. McAllen et al. (1970) showed in a group of 21 asthmatics that when history to house dust and skin prick test to the house dust mite, Dermatophagoides pteronyssinus, were both positive, immediate asthmatic reactions were obtained in $18(86 \%)$ on specific bronchial challenge. Using house dust, Aas and Johansson (1971) obtained positive asthmatic reactions in only $34 \%$ of their subjects selected in a similar way, but with birch and timothy pollens, horse, and fish, positive reactions were seen in $89 \%$ to $100 \%$. It is interesting that in the present study positive prick tests to house dust and $D$. farinae were, equally, the least discriminatory of all the allergens used with regard to positive histories. This suggests that a reliable history of house dust allergy is the least easy to obtain, or that the skin prick test preparations used are the least specific-or possibly both.

In conclusion we feel that the skin prick test coupled with a carefully taken clinical history provides two major advantages in the investigation and subsequent management of asthmatic patients. First, routine skin testing with a selection of common allergens can identify subjects from the population at large in whom allergic factors (particularly inhalant allergens) are most likely to be present and whose asthma is most likely to respond to sodium cromoglycate. Secondly, and more specifically, the test supplies supporting evidence or otherwise to a history of immediate hypersensitivity and so may influence treatment by environmental control or specific desensitization. The relation of an allergen to symptoms must remain in doubt where a positive skin prick test is obtained in the absence of a positive history, or where the history is not supported by the skin test. Where the relevance of a particular allergen is of special importance, nasal or bronchial provocation tests may be considered if the history and skin test prove discordant.

We wish to thank colleagues for submitting patients for investigation, A. V. Swan, Esq., Department of Epidemiology and Social Medicine, St. Thomas' Hospital, for statistical advice, the Medical Illustration Department, Radcliffe Infirmary for preparing illustrations, Miss T. Drysdale for secretarial assistance, and the Clinical Research Board of the Brompton Hospital (D.J.H.) together with Bencards Limited (M.F.D.) for financial support.

\section{REFERENCES}

Aas, K. and Johansson, S. G. O. (1971). The radioallergosorbent test in the in vitro diagnosis of multiple reaginic allergy. Journal of Allergy and Clinical Immunology, 48, 134.

Coca, A. F. and Cooke, R. A. (1923). On the classification of the phenomena of hypersensitiveness. Journal of Immunology, 8, 163.

Ford, R. M. (1969). Aetiology of asthma; a review of 11,551 cases. Medical Journal of Australia, 1, 628.

Forgacs, P. (1973). Skin tests and clinical features of asthma. Paper read to the joint meeting of the British Thoracic and Tuberculosis Association and the Thoracic Society, Nottingham University.

Johansson, S. G. O. (1967). Raised levels of a new immunoglobulin class (IgND) in asthma. Lancet, 2, 951 .

McAllen, M. K., Assem, E. S. K., and Maunsell, K. (1970). House-dust mite asthma. Results of challenge tests on five criteria with Dermatophagoides pteronyssinus. British Medical Journal, 2, 501 .

Pearson, R. S. B. (1958). Natural history of asthma. Acta Allergologica, 12, 277.

Pepys, J. (1973). Types of allergic reaction. Clinical Allergy, 3, Supplement, p. 491.

-, Chan, M., and Hargreave, F. E. (1968). Mites and house-dust allergy. Lancet, 1, 1270.

Rackemann, F. M. (1947). A working classification of asthma. American Journal of Medicine, 3, 601 .

(1958). Professor Willem Storm van Leeuwen and the asthma problem. Acta Allergologica, 12, 407.

- and Edwards, M. C. (1952). Asthma in children. A follow-up study of 688 patients after an interval of twenty years. New England Journal of Medicine, 246, 815.

Smith, J. M. (1973). Skin tests and atopic allergy in children. Clinical Allergy, 3, 269. 
Stenius, W., Wide, L., and Seymour, W. M. (1972). Clinical significance of total IgE and of specific IgE to Dermatophagoides spp. grass pollen and other common allergens. Clinical Allergy, 2, 303.

$-\frac{}{(1971)}, \frac{}{\text { Clinical solford-Strevens, V., and Pepys, J. }}$ common allergens. Clinical Allergy, 1, 37.

Williams, D. A., Lewis-Faning, E., Rees, L., Jacobs, J., and Thomas, A. (1958). Assessment of fective and psychological factors in asthma. Acta Allergologica, 12, 376.

Requests for reprints to: Dr. D. J. Hendrick, Department of Chest Diseases, United Oxford Hospitals, $\vec{O}$ Churchill Hospital, Oxford.

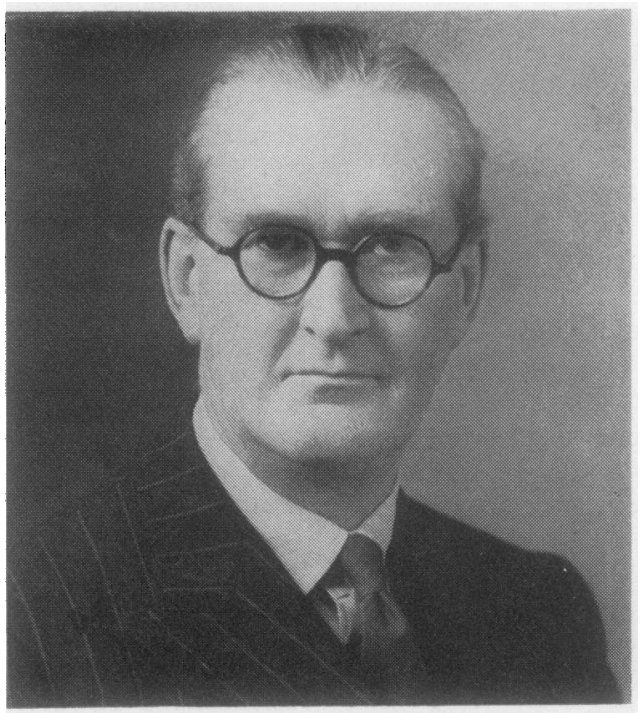

Norman R. Barrett, C.B.E., M.A., M.Chir., F.R.C.S.

After 29 years' continuous service, which included 25 years as editor, Mr. N. R. Barrett is losing his direct connection with Thorax.

The Editorial Committee takes this opportunity of extending to Mr. Barrett their deep appreciation of his vital role in the establishment and subsequent continuing success of the journal and of his very considerable contribution to the literature of thoracic surgery. The Committee hopes that Mr. Barrett will continue to maintain an active interest in the journal for many years ahead. 